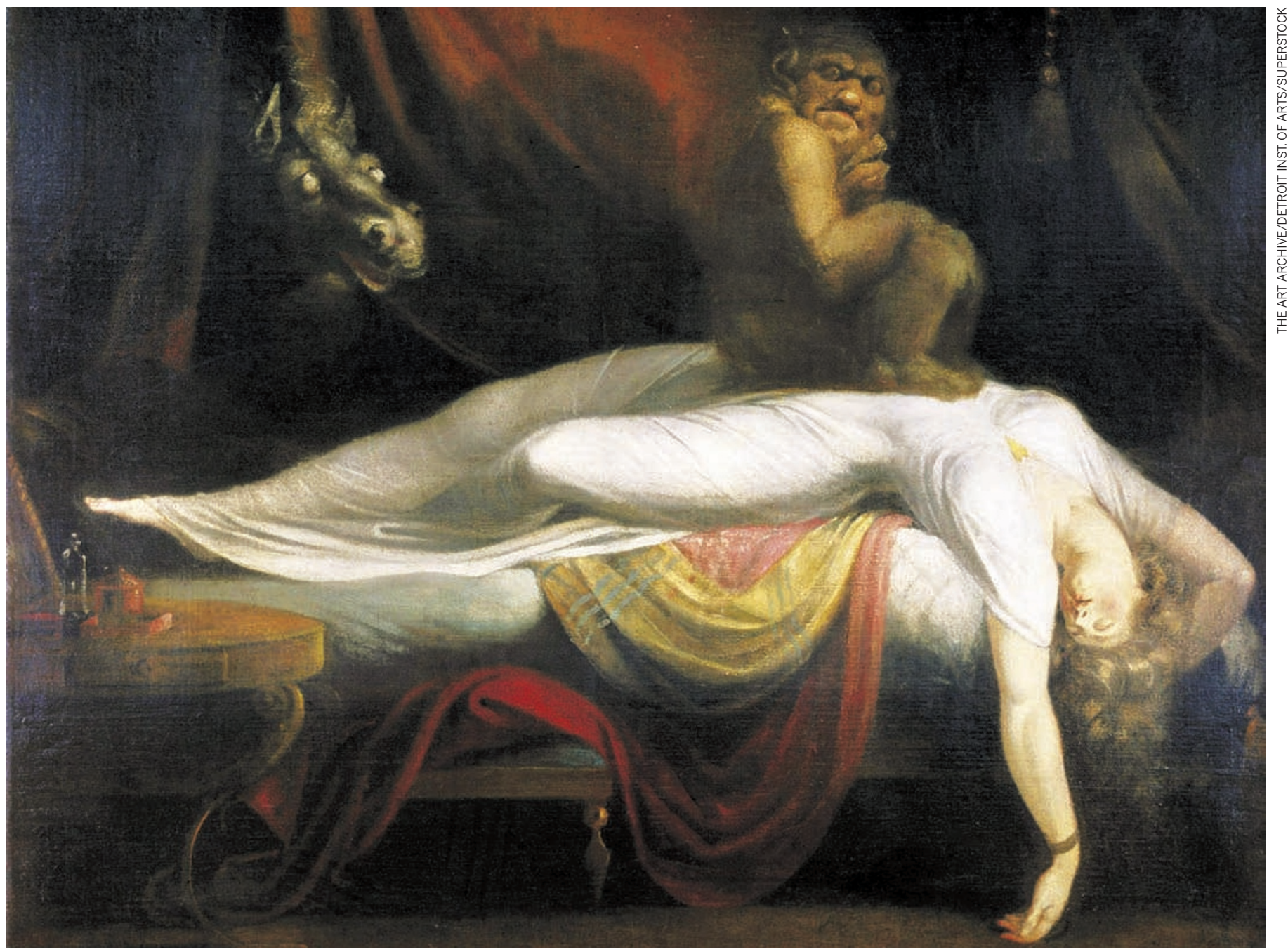

\section{Knowing and feeling}

\section{Owen Flanagan is unconvinced by Antonio Damasio's argument that 'the self' is needed to explain consciousness.}

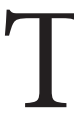

he value of a popular science book depends on the author's ability to sort and present evidence and to be aware of its limitations. In my view, experimental neuroscientist Antonio Damasio stretches too far in his latest work, Self Comes to Mind, in which he considers what the self is and how it connects to consciousness.

Through his series of popular books, Damasio has become a major spokesman for a humane science of the mind that knits together reason and the emotions. His first and rightly celebrated best-seller was Descartes' Error (Harper, 1995). It bemoaned the continuing legacy of what in 1949 philosopher Gilbert Ryle called the "myth of the ghost in the machine", and what Damasio judged "the abyssal separation of mind and body". His later books touched on the neuroscience behind consciousness and free will.

Self Comes to Mind is an upbeat but long-winded and desultory stroll through Damasio's musings on much of what he has thought about or worked on. With more than 90 sections on disconnected topics, each averaging a few pages, his writings come over as a neuroscientist's equivalent of haiku. The grand titles of his essays, such as 'Nature and Culture' or 'Brain and Justice', are not matched by insights. In this piecemeal collection, his thesis is hard to follow; in particular, it is not clear what he means by 'the self'.

Philosophers have conveyed various views of the self over millennia: as an immaterial soul; as some growing brain-pearl that explains feelings of self-identity; the living body; a memory connection to the past; a narrative of who I am. A vast literature has grown up around this deep psychological, philosophical and anthropological problem. Yet Damasio does not engage with it. $\mathrm{He}$ simply criticizes eighteenth-century philosopher David Hume's scepticism that there is a self - writing that Hume "pulverized the self" - and sides with psychologist William James's more embodied approach.

$\mathrm{He}$ also does not engage with the arguments and evidence supplied by cognitive scientists about the connection between consciousness and the self. Damasio offers vague signposts to his thinking: he feels that the self is a process rather than a thing; it is necessary for consciousness; and it requires a 'knower' to be generated in the brain to witness experiences in order for the mind to become conscious. Yet he does not set out scientific evidence to back up these claims.

According to most neuroscientists, consciousness refers to

\section{$\rightarrow$ NATURE.CON}

Martin Heisenberg on free will:

go.nature.com/g4edfx 


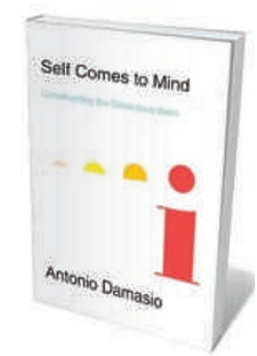

Self Comes

to Mind:

Constructing the

Conscious Brain

ANTONIO DAMASIO

Pantheon: 2010.

384 pp. \$28.95, £25

experience. We seek to explain how consciousness arises from the brain and body and, through evolutionary biology, why it was selected for, emerged and became ubiquitous. Damasio's views on these issues are not fleshed out. As for the mechanism, he recounts the accepted picture that the brainstem,

thalamus and posteromedial cortices play a big part. His 'just-so' answer on the evolutionary function of consciousness is unconvincing.

Damasio gives familiar descriptions of experiences that require an organism but do not require a 'self'. Most basic is simple sensory consciousness, as when an animal experiences pain or pleasure, hunger or thirst (which Damasio calls the protoconsciousness). Then there are more extended experiences, as when a raccoon foraging at a stream takes in the sights, smells and sensations of its surroundings (Damasio's core consciousness). And there is self-consciousness - possibly unique to humans - that includes awareness of self-referential feelings such as anxiety, or the story of one's life or character (autobiographical consciousness).

Present in all these types of consciousness, he says, is a 'self process'. This may be involved in the 'self as witness' or the 'self as protagonist', but it is not clear why it is necessary for the 'self as experiencer'. In fact, Damasio explicitly excludes dreaming - in which the sleeper has experiences but lacks self-awareness - from the set of conscious experiences. This is obviously unwarranted. We have experiences when dreaming and while under anaesthetic, even though aspects of our awareness disappear. Dreaming does not require a self process, so consciousness does not either.

Just because 'self' is in our vocabulary does not mean that it has any explanatory role in a science of the mind. Damasio says nothing convincing as to why, in addition to our fully embodied conscious beings, we ought to add the self, or self processes, to the ontological table of elements.

Owen Flanagan is James B. Duke

Professor of Philosophy and professor of neurobiology and of psychological and brain sciences at Duke University, Durham, North Carolina 27708, USA. e-mail:ojf@duke.edu

NEUROSCIENCE

\section{Mind your head}

Josie Glausiusz enjoys a thought-provoking exhibition.

$\mathrm{T}$ To step into the human brain is like being plunged into a pulsating bowl of psychedelic spaghetti. At least, that is the sensation visitors experience on entering the Brain exhibition at the American Museum of Natural History in New York. Bursts of light rush along a gigantic jumble of salvaged wires that hang from a ten-metrelong walkway. The installation, by artist Daniel Canogar, simulates the frenetic activity of neurons as they fire electrical impulses.

The real human brain - a plastinated example of which is on display — seems puny after such a dramatic artwork. Yet this complex organ, weighing only 1.4 kilograms and filled with 100 billion neurons, has enabled humans to colonize the planet, create great works of art, build robots and rockets, calculate and cogitate, fall in love and be conscious of our own existence. The exhibition covers all this and more.

An enchanting video captures many of the brain's functions. As a graceful young dancer performs pliés and pirouettes in an audition, a large-scale replica of the brain lights up different regions as they become active. Her cerebellum coordinates movement and balance; her limbic system triggers emotions and memories; her auditory cortex interprets music; and her motor cortex sends messages to her muscles. When she is nervous, her amygdala triggers regions of her brainstem to send signals to her heart, speeding its beat. Using her prefrontal cortex, she consciously controls her breathing to calm herself down. When she learns she has passed her test, her hippocampus allows her to save the happy memory in long-term storage.

Emotions play a big part in how our brains work, often overriding rational decisionmaking. There is a reason for that, says Margaret Zellner, a behavioural neuroscientist at New York's Rockefeller University and a consultant to the exhibition. "A lizard brain is a very reflexive, automatic system," she says, pointing to a stuffed green iguana on

\author{
Brain: The Inside \\ Story \\ American Museum of \\ Natural History, \\ New York. \\ Until 15 August 2011.
}

display. By contrast, the mammal brain makes us much more flexible thanks to our limbic system. It generates emotions that are key to our everyday survival and forms memories. If the limbic system is damaged, "our social interactions are disrupted, and we are much more impaired than if we lose the ability to speak," explains Zellner.

A panel shows some of the latest medical advances to help those who have other kinds of brain impairment. Deep brain stimulation, in which a battery-powered, implanted neurostimulator triggers electrical activity in areas of the brain that control movement, has been used to treat more than 80,000 people with Parkinson's disease. Transcranial magnetic stimulation, the fastestgrowing non-drug treatment for major depression, uses a large electromagnetic coil placed against the scalp to generate painless electric currents that stimulate brain cells involved in mood control. It could some day be used to treat schizophrenia and bipolar disorder. Other devices use electrodes to restore sight by stimulating neurons in the retina, or allow people with limb paralysis or no limbs to move a cursor on a computer simply by thinking about it.

Even more awe-inspiring is another dangling tangle of copper wires, again courtesy
Brain highlights the Kiki and Booba experiment: $98 \%$ of people agree on which name matches which shape, regardless of their native language. of Canogar, depicting the developing infant brain in utero. In the first five months of fetal development, an astonishing 500,000 neurons form every minute. Millions of connections continue to be made in the first few months of life, and each new skill stimulates the growth of neural links - even into adulthood and old age. Such development is the goal of exhibition curator Rob DeSalle: "I want people's brains to change as they go through this exhibition - for the better," he says. .

Josie Glausiusz is based in New York City. e-mail:jg@planetjosie.net 